\title{
Meaningful affordances
}

\author{
Roy Dings ${ }^{1}$
}

Received: 18 June 2020 / Accepted: 4 September 2020 / Published online: 18 September 2020 (c) The Author(s) 2020

\begin{abstract}
It has been argued that affordances are not meaningful and are thus not useful to be applied in contexts where specifically meaningfulness of experience is at stake (e.g. clinical contexts or discussions of autonomous agency). This paper aims to reconceptualize affordances such as to make them relevant and applicable in such contexts. It starts by investigating the 'ambiguity' of (possibilities for) action. In both philosophy of action and affordance research, this ambiguity is typically resolved by adhering to the agents intentions and concerns. I discuss some recent accounts of affordances that highlight these concerns but argue that they tend to adopt an 'atomistic' approach where there is no acknowledgement of how these concerns are embedded in the agents wider concerns, values, projects and commitments. An holistic approach that does acknowledge this can be found in psychological research on agents having a sense of what they're doing. I will discuss this research in the second part of the paper and argue that agents can analogously have a sense of what is afforded. This is deemed the entry point for understanding the meaningfulness of affordances. In the final part of the paper I apply this analysis to recent attempts which seek to make sense of authentic and autonomous agency in terms of affordances.
\end{abstract}

Keywords Affordances · Agency · Phenomenology $\cdot$ Autonomy $\cdot$ Meaningfulness · Relevance

\section{The problem of meaningful affordances}

Although devised in the 1960s and 1970s in the context of visual science, the notion of 'affordances' has recently become widespread in more general cognitive science and beyond (Rietveld and Kiverstein 2014; Heras-Escribano 2020). Affordances are typically construed as possibilities for action offered by the environment-such as a

\footnotetext{
$凶$ Roy Dings

r.p.j.m.dings@gmail.com

1 Institute for Philosophy II, Ruhr-University Bochum, GA 3/140, 44780 Bochum, Germany
} 
chair affording 'sitting on', people affording 'talking to' and paperweights affording 'picking up'.

Despite its widespread application, the notion of 'affordance' is not without controversy. There have been many debates about the ontological status of affordances, their purported normativity and whether they require the positing of content (Chemero 2003; Michaels 2003; Rietveld 2008; Heras-Escribano 2020). The present paper focuses upon another controversy surrounding research on affordances, which questions the extent to which the concept fully captures what matters to individuals acting upon or being solicited by affordances.

Certainly, Gibson's $(1966,1979)$ theory of affordances constitutes a landmark in research on meaningful experience, as it provides what is arguably the first scientifically plausible framework for the study of how agents meaningfully perceive and interact with their environment. Moreover, the relational nature of affordances allowed for an understanding of meaning which did not solely equate it with subjectivity but, rather, took into account its subjective and objective aspects. Gibson's original theory was, however, limited in scope when it comes to accounting for meaning. ${ }^{1}$ Costall (1995, p. 468), for instance, criticized "its confinement to an essentially privatized conception of meaning", and aimed at refining the notion of 'affordance' so as to incorporate the social and cultural constituents of meaningfulness (see also Heft 1989). More recently, much excellent work has been done to further refine the Gibsonian concept of 'affordance' so as to do justice to the complexities of agential phenomenology (e.g. Withagen et al. 2012; De Haan et al. 2013; Rietveld and Kiverstein 2014; Baggs and Chemero 2019).

Nevertheless, some still worry that affordances may not be suitable for differentiating between 'merely relevant' possibilities for action and meaningful possibilities for action [see e.g. the replies by Mojica (2020) and Dings (2020b) to Heras-Escribano (2020)]. For instance, we find this worry in a forthcoming paper by Ratcliffe and Broome (in press), who question "the utility of the affordance concept-whether, when and how it serves to illuminate something that would be murkier without it" (ibid.). The core of their criticism is that the notion of 'affordance' is "insufficiently discerning" and "lacks the required discriminatory power" (ibid.) for explaining what I have here called 'meaningful experience'. We find this criticism also voiced in Ratcliffe $(2015$, p. 61 , note 24$)$, who notes that

Things do not simply 'afford' activities; they appear significant to us in all sorts of ways. It is not helpful to say that a bull affords running away from, while a cream cake affords eating. What is needed (...) are distinctions between the many ways in which things appear significant to us.

The worry, then, is this: things matter to us in various ways, and the concept of 'affordance' fails to accommodate this diversity in mattering. Similarly, whilst affordances are sometimes said to be relevant or salient (cf. Rietveld 2012 on 'real relevance';

\footnotetext{
1 For extensive discussion of the revolutionary nature of Gibson's proposed account of meaning and its subsequent effect on various authors and disciplines, see Heft (2001). In Dings (2020b) I suggest that Gibson's research shifted towards an increasingly narrow conception of meaning, which might explain why ecological approaches have had little influence upon psychological accounts of meaning (see e.g. Markman et al. (2013) and Arndt et al. (2013).
} 
Rietveld and Kiverstein 2014; Brancazio and Segundo-Ortin 2020), things can be relevant and salient in various ways. So, how can the 'affordance' concept capture the many ways in which something could matter or be significant? How can an affordance, or a field of affordances (cf. De Haan et al. 2013; Rietveld and Kiverstein 2014), be meaningful?

This worry leads to the following problem: if affordances cannot capture the diverse ways in which things can matter to an individual, then the concept of 'affordance' is not suitable for application in contexts wherein that diversity plays an important role. ${ }^{2}$ Let me highlight three such contexts:

(1) Consider the clinical or psychiatric contexts that Ratcliffe and Broome seem particularly worried about. In the case of psychopathological experience, we do indeed need to be able to accommodate alterations in how things matter to the patient, in order to properly understand their condition.

(2) Many theories in cognitive science that employ the terminology of affordances also make use of phenomenological considerations specific to them. This can be because experiences of salience and relevance are indispensable for understanding the dynamics of affordance interaction. Alternatively, it may be because staying true to the phenomenology of our experience is seen as an important benchmark which must be met, if we are to provide a good explanation for interacting with affordances. In both cases, a detailed description of that phenomenology is pivotal.

(3) More recently, there have been attempts to investigate normative and existential issues, such as authentic and autonomous agency, in terms of affordances (see e.g. De Haan et al. 2013; Gallagher 2018a, b).

This paper will be geared towards contributing to context (3). In Sect. 4, I will argue that mere possibilities for action do not contribute to authenticity and autonomy in any interesting sense. Rather, only particularly meaningful possibilities do. Importantly, however, the analysis that I put forward in this paper will also have ramifications for context (2). ${ }^{3}$ Specifically, it offers a contribution to enactive approaches to cognition that employ the 'affordance' concept (e.g. Rietveld and Kiverstein 2014; Colombetti 2014; Gallagher 2017). Such enactive views aim to do justice to the lived experience of agents, but this requires a more refined understanding of meaningful experience than that present in extant accounts of affordances.

Thus, this paper is founded upon and motivated by the acknowledgement that the concept of 'affordance', as it stands, cannot accommodate the full diversity of how things might matter to an agent. But, instead of therefore discarding talk of affordances (as suggested by Ratcliffe and Broome (in press) and recent work in the psychology of meaning), this paper seeks to provide a framework that re-conceptualizes affordances, such that they do justice to the rich phenomenology of mattering, thereby making the concept 'affordance' more suitable for the investigative contexts outlined above. In doing so, I draw on, and seek to supplement, recent work on the topic of how

\footnotetext{
2 This limits the scope of this paper: there are various domains within cognitive science and issues in ecological psychology that do not speak to this diversity of how things can matter to agents. The claims of my paper are therefore not relevant to those domains and issues.

${ }^{3}$ I address the first context, of psychiatry and psychopathology, in Dings (2020a). See also De Haan (2020).
} 
affordances are experienced (e.g. Withagen et al. 2012; De Haan et al. 2013; Rietveld and Kiverstein 2014).

In order to achieve this aim, the paper is set up as follows. In Sect. 2, I explain why contemporary research on affordances fails to capture meaningful experiences. I start by drawing on some ideas from philosophy of action in order to highlight the fact that one and the same instance of behavior can be construed in terms of, or implicated within, many different actions. The presumed solution to this puzzle requires consulting the agent's intentions, goals and ongoing projects-which I here subsume under the label "concerns" ${ }^{4}$-in order to determine the particular action carried out in such instances. Importantly, these concerns are diachronic in nature because they span multiple timescales. I go on to discuss some recent research on affordances that does acknowledge the diachronicity of concerns. However, I will argue that this research fails to sufficiently account for meaningful experience because it tends to adopt an atomistic approach to diachronicity by isolating the concern to which an affordance is relevant from other concerns and agential characteristics. Instead, I will argue that what is required is a holistic approach that emphasizes not only that intentions are spread across various time-scales, but also that these intentions are embedded in e.g. the agent's personal values, commitments, self-narratives and so forth. In Sect. 3 I will show that such a holistic approach is present in existing psychological research on agents having a sense of what they are doing. I will suggest that we can analogously think of agents having a sense of what is afforded (which, similarly, is intertwined with their diachronic concerns). This is deemed to be the entry point to understanding the meaningfulness of affordances. Then, in Sect. 4, I show how this proposal is beneficial for thinking about authenticity and autonomy in terms of affordances. I conclude in Sect. 5 by summarizing the key points of my argument and identifying avenues of future research.

\section{Why existing research on affordances fails to fully accommodate meaningful experience}

\subsection{The ambiguity of action}

Affordances are typically construed as 'possibilities for action offered by the environment to an agent'. However, as we know from the philosophy of action, individuating a particular action from a range of possible acts can be problematic. In the words of MacIntyre (1984, p. 206):

It is a conceptual commonplace (...) that one and the same segment of human behavior may be correctly characterized in a number of ways. To the question 'What is he doing' the answers may with equal truth and appropriateness be 'Digging', 'Gardening, 'Taking exercise', Preparing for winter' or 'Pleasing his wife'", (p. 206)

\footnotetext{
4 This term is commonly used in affordance-research (cf. De Haan et al. 2013; Rietveld and Kiverstein 2014; Dings 2018; Jeuk 2019; Brancazio and Segundo-Ortin 2020).
} 
Although philosophers of action are, of course, interested in actions, the current proposal starts from the assumption that investigations into the structure of action can also be relevant for understanding the experience of possibilities for action. For instance, when MacIntyre's gardener walks into his garden, what does this garden (or particular objects in it) afford? More specifically, what does he experience those objects as affording? Digging? Taking exercise? Pleasing his wife?

Philosophers of action tend to focus on agents' intentions when it comes to individuating actions (that is, determining what action is being performed by a given agent, see e.g. Goldman 1970). In research on affordances, the relevance of intentions and intentional actions has been acknowledged, for instance, by Heft (1989). He argued that the affordances we perceive are a function of our intentions, goals and concerns:

A lighted candle not only affords pain, if you touch its flame, but more positively it also affords illuminating a dark place as well as heating a liquid such as water. Which of these latter two dispositional qualities is realized in experience depends on the individual's behavioral goals or intentions at a particular time (Heft 1989, p. 16, italics in original text)

Following Merleau-Ponty, Heft highlighted that we should not construe these intentions as being overly mentalistic (ibid., p. 11). Rather it is through our bodily engagement with affordances that we realize (or implement) these supposedly 'abstract' intentions (Dings 2019).

But although Heft is to be applauded for bringing into focus the importance of intentional behavior in discussions about affordances, he has not sufficiently appreciated what we could call the diachronic nature of these intentions. That is, an intention is always connected to other intentions, spanning multiple time scales. Again, MacIntyre succinctly conveys this idea when he writes the following:

Consider another equally trivial example of a set of compatibly correct answers to the question 'What is he doing?' 'Writing a sentence'; 'Finishing his book'; 'Contributing to the debate on the theory of action'; 'Trying to get tenure'. Here the intentions can be ordered in terms of the stretch of time to which reference is made. Each of the short-term intentions is, and can only be made, intelligible by reference to some longer-term intentions; and the characterization of the behavior in longer-term intentions can only be correct if some of the characterizations in terms of shorter-term intentions are also correct. Hence the behavior is only characterized adequately when we know what the longer and longest-term intentions invoked are and how the shorter-term intentions are related to the longer. Once again we are involved in writing a narrative history (1984, pp. 207-208)

Thus, a necessary step for understanding actions (and also, I want to argue, meaningful possibilities for action), is taking into account what I will call the agent's diachronic concerns. Roughly put, these include the agent's goals, projects, commitments and intentions across various timescales, as well as the interrelation of these goals and intentions across said timescales. Let me elaborate on these diachronic concerns and their implications for what we could call personal agency. 


\subsection{Personal characteristics of agency: diachronic, self-interpretative and social}

Various authors have recently highlighted the importance of personal agency, that is, of personal characteristics and the agent's diachronic concerns, for understanding how we perceive and act upon affordances (see e.g. McGann 2007; Dings 2018; Withagen 2018; Weichold 2018; Baggs and Chemero 2019; Jeuk 2019; Brancazio and SegundoOrtin 2020). Some reckon that these personal characteristics are required to fully understand interactions with affordances, as averting to bodily make-up, skills and abilities, and social and cultural embeddedness might not alone suffice for explaining agent-environment interactions. For instance, Jeuk (2019), in response to Ratcliffe's worry that affordances cannot properly account for meaningful experiences, notes that "embodied abilities do not constitute what matters to us-teaching a lecture does not matter to me because I have the ability to do so, but because I have concern to do so. A conception of motivation, interest or relevance that goes beyond embodied abilities is needed here" (p. 255).

Before showing how my proposal differs from that propounded by these authors, who also highlight the importance of diachronic concerns, let me first say a bit more about the core components of personal agency: its diachronic, self-interpretative and (perhaps somewhat paradoxically) social nature.

First, as already emphasized, human agency is fundamentally diachronic. What we do now is often inextricably connected to what we have done in the past and what we plan to do in the future. This point is particularly relevant for making sense of our experience of meaningfulness. As Ratcliffe (2017, p. 155) notes:

[L]onger-term commitments and projects give the significance of our surroundings a greater coherence and temporal consistency. Insofar as our concerns are stable, things will matter to us in consistent and enduring ways.

Our intentions and concerns indeed span multiple timescales (McGann 2007; Jeuk 2019; Brancazio and Segundo-Ortin 2020). On the one hand, accounting for this requires taking into consideration the agent's ontogenetic and phylogenetic history (Withagen et al. 2012). Regarding the agent's ontogenetic history, i.e. their personal past, memory might play an important role in modulating affordance perception by making certain affordances meaningful. ${ }^{5}$ In this regard, consider a proposal by Glenberg (1997), which starts by highlighting the need for memory in the context of differentiation: whilst various paths afford taking and various people afford talking to, oftentimes what we need is the path home or a particular individual to talk to, and so we need to be able to differentiate between relevant and irrelevant affordances. Glenberg notes that although an optical flow field might contain information for perceiving an affordance, it does not contain information about the affordance's relevance to you. Thus, memory (that is, previous embodied interactions with this object) is combined (or, to use Glenberg's term, meshed) with the perception of the affordance and, in this manner, "a path becomes the path home and the cup becomes my cup" (ibid.,

\footnotetext{
${ }^{5}$ For a more ecological perspective on how past experience may modulate affordance-perception without drawing on memory, see Michaels and Carello (1981). My thanks to an anonymous reviewer, for bringing this book to my attention.
} 
p. 4). According to Glenberg, it is only the combination or meshing of perception and memory that "make[s] the environment meaningful to that person" (ibid., p. 17). Note here how this is important for present purposes: whilst all glasses of water on the table are relevant for quenching thirst, and thereby 'matter' to agents in this sense, my glass of water matters to me differently than the other glasses do.

On the other hand, the diachronic nature of an agent's concerns means that a person's future is also relevant for affordance-perception. In this respect, Van Dijk and Rietveld (2018) offer an account of how skilled agents may anticipate affordances: the idea is that various affordances are 'nested' so that engaging with one affordance leads to another affordance becoming relevant, and so situations naturally envelope (or develop into) one another. The affordances are said to "unfold" and thereby set up the conditions for continuing agency. This sheds light on how diachronic agency might take place (for another proposal on how our engagement with distal affordances might be understood, see Brancazio and Segundo-Ortin 2020).

To integrate both past and future concerns into our present activities, we can also make use of narrative. As MacIntyre (1984) already pointed out, integrating short-term and long-term intentions actually amounts to forming a narrative. Moreover, theories on narrative identity are specifically devised to accommodate both minor changes and major shifts in self-understanding and worldly interaction.

In Dings $(2018,2019)$ I developed the idea of narrative self-programming which entails that, during moments of narrative deliberation, one tries to make oneself responsive to certain possibilities for action. On this view, abstract long-term intentions (e.g. to be more assertive) are typically realized through concrete short-term intentions, such as 'implementation intentions' (e.g. I should speak up the next time a colleague fails to properly address my question during a business meeting). I suggest that the interrelation between these intentional forms possesses a narrative structure: the act of speaking up is only made intelligible when we take into account the goal of wanting to be more assertive, which in turn is only made intelligible by considering its embedding in a holistic structure of concerns. ${ }^{6}$

This emphasis on narrativity also fits well with another crucial element of personal or human agency: its reflective or self-interpretative character. As Taylor (1985, Chapter 2) famously argued, human beings are self-interpreting animals. What is at stake here-and again, this is underappreciated in existing work on affordances- is that human agents reflect upon their agency, discuss it with their peers and loved ones, and can shape or alter it (cf. Brancazio and Segundo-Ortin 2020). Indeed, the idea of narrative self-programming can also be construed as follows: someone becomes aware of their field of affordances and, for various reasons or concerns, tries to alter it. This is the active element of the diachronicity of human agency, which foregrounds the importance of intentions, as it is through intentional behavior that people self-regulate.

The diachronic and self-interpreting nature of personal agency is intertwined with the social and cultural embeddedness of such agency. This embeddedness has received much more attention in the literature on affordances than its diachronicity and selfinterpretive nature (see e.g. Heft 1989; Costall 1995; Rietveld 2012; Ramstead et al.

\footnotetext{
6 Given the contested nature of narratives, if one feels that "embedding in a holistic structure of concerns" does not equate to narrativity, one can simply substitute the term 'narrative' with "diachronic meaningful self-understanding" (for related discussion on this point, see Brandon 2016).
} 
2016). Interestingly, Costall (1995) appears to have undertaken a similar project to the one pursued here: he aimed to make Gibson's original notion of 'affordance' more hospitable to meaningfulness. According to Costall, people are not taught what an object happens to afford, but what it is meant to afford (ibid., p. 472). For instance, a chair affords standing on and throwing, but what it is meant for (in our culture) is sitting upon. This is what Costall (2015) calls its 'canonical' affordance. In a nutshell, to understand the meaningfulness of affordances we need to take into account their fundamentally social nature and thus how they are 'culturally derived' (Heft 1989).

\subsection{Acknowledging the richness of agential phenomenology: atomistic diachronicity versus holistic diachronicity}

We started this section by acknowledging that we can only understand action by taking into account the agent's diachronic concerns. Analogously, we can only understand possibilities for action (i.e. affordances) if we take into account the agent's diachronic concerns. This point has been highlighted by various researchers that I briefly discussed in the previous subsection. But although they do accommodate diachronic concerns, they do not sufficiently elaborate on how these diachronic concerns lead to a rich phenomenology. This is problematic for two reasons.

Firstly, many researchers use phenomenological criteria (that is, remaining true to 'what it is like' to experience) as benchmarks for what is required in a proper explanation of interacting with affordances. In particular, enactive approaches to cognition (including the ecological-enactive accounts of e.g. Rietveld and Kiverstein 2014; Brancazio and Segundo-Ortin 2020) aim to do justice to the lived experience of the agent. That is, on an enactive approach to cognition the agent's phenomenology is heavily intertwined with behaviour. As such, one cannot fully grasp interaction with affordances if one does not take into account the richness of agential phenomenology.

Secondly, experiences of salience and relevance typically play a functional role within explanations of interacting with affordances. That is, in many of the above referenced accounts, it is acknowledged that experiencing relevance concretely affects how we interact with affordances. For example, the influential Skilled Intentionality Framework $(S I F)$ assumes that skilled intentionality involves the capacity to distinguish relevant from irrelevant affordances (Bruineberg and Rietveld 2014; Rietveld and Kiverstein 2014). Moreover, it is experiences of relevance (of inviting or soliciting affordances) that determines the 'direction' of our future anticipation of affordances (Van Dijk and Rietveld 2018). Although SIF goes a long way toward accounting for the agent's phenomenology, it too seems to rely on a simplified or otherwise limited understanding of relevance (but see Rietveld 2012 on 'real relevance').

Thus, although many researchers acknowledge the importance of phenomenology for explaining affordances, they often fail to provide analyses which fully capture the richness of agential phenomenology. Instead, they work with a simplified picture in which the agent 'experiences relevance' or 'experiences salience'. But, as we saw in the introduction, an object's affordances can be experienced as relevant in many diverse ways. However, none of the existing accounts of 'affordance' fully accommodate that diversity and thus they all fall within the reach Ratcliffe and Broome's criticism (in 
press). So how does the current proposal differ from those of the authors discussed so far, such that it can accommodate the diverse ways in which things matter to an agent?

The main difference pertains to the extent to which diachronic concerns are understood atomistically or holistically. ${ }^{7}$ An atomistic approach might appreciate that intentions span across multiple timescales (and thus be diachronic in this sense), but fail to appreciate that those intentions are always embedded in other concerns or personal characteristics of the agent. Consequently, such atomistic approaches will still end up with an impoverished notion of relevance, because a tasty ham sandwich, for instance, will be experienced as 'merely relevant' only due to its relevance to the agent's hunger. In contrast, a more holistic approach will emphasize precisely the embeddedness of this concern. That is, on a holistic view, the agent's concern of being hungry will be considered inextricable from not only various other concerns (again, across multiple timescales), but also from personal characteristics such as values and self-narratives (Gallagher 2012) For instance, the agent might be a vegetarian, and thus the ham sandwich is not experienced as 'merely relevant'. Rather, its affordances come with a much richer phenomenology, due to the embeddedness of the concern of hunger within the agent's more wide-ranging personal values, social commitments, and cherished self-image.

Thus, I want to argue that we can only fully understand the meaningfulness of affordances if we take into account both atomistic diachronicity (agents' intentions or goals are spread across multiple timescales) and holistic diachronicity (intentions and goals are themselves embedded in agents' values, commitments and self-narratives). Whilst work on affordances does sometimes account for the former kind of diachronicity, the latter is typically left underdeveloped, or else left entirely ignored. Now that we know how the current proposal differs from existing research in the area, we can fully appreciate the scope of this paper. Its aim is not to provide a fully fleshed out theory of meaningful affordances, let alone an empirically validated one-much more work needs to be done in order to achieve that aim. Rather, this paper has the much more modest aim of exploring an intuitively plausible re-conceptualization of 'affordance' (in Sect. 3), and then determining the beneficial consequences of this re-conceptualization for research on autonomy and authenticity (in Sect. 4), as well as identifying some key areas for future research (in Sect. 5).

\section{Having a sense of what one is doing and a sense of what is afforded}

Let us briefly recap what has thus far passed by returning to the problem of action individuation which we encountered at the start of Sect. 2. The behaviours undertaken by MacIntyre's gardener can be described in terms of a variety of different actions (he is digging, or preparing his garden for winter, and so on). In order to resolve this ambiguity and so clarify precisely what the gardener is doing, we need to, from a third-person perspective, explicitly refer to the gardener's diachronic concerns (his short-term intentions or a particular desire). For instance, we must refer to his intention to prepare the garden for winter in order to subsequently label his action 'preparing

\footnotetext{
7 Thanks to Jelle Bruineberg for suggesting this terminology.
} 
the garden for winter'. However, from a first-person perspective (i.e. the agential perspective), those diachronic concerns are implicit in the action. As in typical everyday cases, the gardener himself need not reflect on his diachronic concerns to make sense of what he is doing. Rather, he already has a sense of what he is doing. Put otherwise, he does not need to explicitly or reflectively adhere to his diachronic concerns because, in an important sense, he 'is' these concerns: he enacts them. ${ }^{8}$ Consequently, from the agential perspective there is a large degree of certainty in his actions, and very little ambiguity as to what he is doing.

In this section I will elaborate on this 'sense of what one is doing' and will argue that the gardener, aside from having a sense of what he is doing, also has a sense of what is afforded. This observation offers an entry-point into seeing how diachronic concerns modulate our experience of relevance, and thus enables an account of affordances that does justice to the variety of ways in which things matter to the agent.

\subsection{Having a sense of what one is doing}

In the late 1980s, the psychologists Robin Vallacher and Daniel Wegner targeted the question of how we are capable of individuating action from a psychological perspective. They wondered how people manage to successfully individuate actions in spite of the fact that any behavior can be described in numerous different ways. Combining theoretical work from the philosophy of action with their own experimental research, they came up with Action Identification Theory (AIT), whose core claim is that people indeed have a sense of what they are doing whilst acting (see e.g. Vallacher and Wegner 1987, 1989, 2011). More specifically, AIT posits that people use different levels of action identification. This means that an action is 'identified' on a particular level within a hierarchy that ranges from relatively low to relatively high. Regarding this point, they note the following:

The multiple act identities for an action tend to be organized in an hierarchical manner. Lower-level identities in the hierarchy convey the details or specifics of the action and thus indicate how the action is performed. Higherlevel identities provide a more general understanding of the action; they indicate why the action is performed or what its effects and implications are. Higherlevel identities are less movement-defined than lower-level identities, and provide a more abstract and comprehensive understanding of the action. (ibid., p. 330)

Consequently, low- and high-level actions relate to each other in a hierarchical manner. For instance:

One 'goes to work' by 'driving a car', one 'drives a car' by 'stepping on the pedals and turning the steering wheel', and one 'steps on pedals and turns the wheel' by 'moving one's arms and leg'. (ibid. p. 331. See also Goldman 1970 on such 'generative' relations)

\footnotetext{
$\overline{8}$ My thanks to an anonymous reviewer for suggesting this phrase.
} 
But how do these various levels of identification figure in the dynamics of human agency? On the basis of their research, Vallacher and Wegner posit three theoretical principles that explain how these levels relate to actual actions. The first principle states that action is maintained with respect to its prepotent identity: an identification is always made at some level, and this identity "functions as an intention to initiate an action, a frame of reference for performing the action, and a criterion to assess how well the action has been performed" (ibid., p. 331). Vallacher and Wegner's second principle says that "when two or more plausible identities are available, people are inclined to choose the identity that provides the most comprehensive understanding of what they are doing, plan to do, or have done" (ibid., p. 332). The third principle maintains that, when a (relatively) high-level action identity is not effectively exhibited or performed, there is a tendency to adopt a lower-level identity. In other words, when actions are complex, unfamiliar, time-consuming or being disrupted, agents tend to shift towards a lower-level identity.

The elaborate framework of AIT covers much of human agency. For instance, AIT offers an extensive analysis of the factors which contribute to action identification, such as action difficulty, familiarity, complexity, enactment time and learning time (Vallacher and Wegner 1987). It also sheds light on the stability and flexibility of action and has been used to study the development of expertise (ibid.). Furthermore, AIT can be used to make sense of individual variations in agency. According to Vallacher and Wegner, people differ in their 'level of personal agency', that is, the degree to which they organize their behavior in terms of abstract meaningful categories or concrete 'how' actions (Vallacher and Wegner 1989). This level of personal agency has implications for individuals' self-conception and also the study of phenomena like emotion (ibid.). It is also noteworthy that AIT makes predictions about optimality in behavior (i.e. the successful balancing of low- and high-level action identification), and that it makes use of dynamical systems theory in this regard (Vallacher and Wegner 2011).

\subsection{Having a sense of what is afforded}

I want to propose that agents similarly have a sense of what is afforded. That is, agents identify not only their own actions, but also the action-possibilities that objects afford. Consider, in this vein, MacIntyre's gardener, who, whilst entering his garden, experiences it (or particular objects therein) as affording 'taking exercise' or 'preparing for winter'. Or, to make use of another of MacIntyre's examples, think of how the laptop or typewriter is experienced as affording 'writing a sentence' and/or 'finishing a book'. The point brought to the fore by these examples is that, from the agent's phenomenological perspective, there is a relative certainty as to what is afforded. And what is afforded, or, more specifically, what is experienced as being afforded, can be understood in an analogous fashion to AIT's distinction between low- and high-level identifications. That is, some affordances are experienced as low-level, specifying the movements that are afforded, whereas other affordances are experienced as more high-level, specifying the reasons or long-term goals that are relevant. These latter 
affordances can be colloquially described as meaningful in the sense that they provide possibilities-for-meaningful-or-high-level-identity-actions. ${ }^{9}$

Recall that, in AIT, higher-level identifications target the 'why' of action (as opposed to lower-level identifications, which target the 'how'). Similarly, an experienced possibility for action which is identified at a higher-level will contain a purposive 'why' element. In such a case, the long-term goal (or diachronic concern) is part of the phenomenality of agency (cf. Gallagher and Marcel 1999; Horgan et al. 2003). For instance, an empty soda can on the ground can be experienced as affording picking up (a low-level 'how' identification), but also as affording cleaning the street or contributing to society (high-level, 'why' identification, which specify the embeddedness of one's diachronic concerns, in this case contributing to society). This embeddedness of meaningful actions entails more "integrated" behavior, "presumably because the agent's intentions encompass more than the immediate action itself, their attention focus goes beyond it, and its significance is part of the larger projects and concerns of the person" (Gallagher and Marcel 1999, p. 12). Indeed, 'why' identifications highlight the embeddedness of action in agents' lives by enabling us to consider actions from a broader and more temporally extended perspective (holistic diachronicity). They show us what the action(-possibility) means to the agent. ${ }^{10}$

\subsection{Acts of identification and worries about Cartesianism}

At this point, one might worry that the current proposal's use of action identification theory makes it incompatible with the ecological tenets of the concept of 'affordance'. ${ }^{11}$ This is because AIT prima facie seems to adopt precisely the sort of Cartesian framework that Ecological Psychology (EP) has so desperately tried to get rid of. For instance, Vallacher and Wegner (2011, p. 328) suggest that AIT offers "a parsimonious model of the mental control of action" according to which "the immediate precursor to action is a mental representation of what one is doing" (Vallacher and Wegner 1987,

\footnotetext{
9 An anonymous reviewer pointed out that Shaun Gallagher, in a recent book that was published while writing this paper, similarly discusses affordances, philosophy of action and AIT. However, Gallagher (2020) primarily focuses on elucidating action (and social interaction) for which he draws on affordance research and AIT. Conversely, the current paper aims to elucidate affordances and draws on philosophy of action and AIT to do so. More importantly, the current paper primarily targets the issue of differentiating the various ways in which something might matter to an agent (e.g. an affordance being 'merely relevant' or 'meaningful'). This is not the focus for Gallagher. He touches upon this issue at some points in the book, but given his aim to investigate social interaction, these passages tend to be restricted to social forms of meaning. In contrast, the current paper emphasizes personal meanings (which may nevertheless be socially embedded). Although an analysis of the similarities, differences and mutual implications of Gallagher's book and this proposal would be worthwhile, this is beyond the scope of the current paper.

10 Another factor that might modulate how something matters to agents is the psychological distance experienced between themselves and the object interacted with. Construal Level Theory, which draws on AIT and similarly distinguishes between low-level (concrete) construal's and high-level (abstract) construal's, includes four forms of psychological distance (social, hypothetical, temporal, and spatial), all of which have an effect on how we experience and interact with objects: "For example, on a rainy day, it matters whether an umbrella one notices belongs to a friend or to a stranger (social distance); in the jungle, it is important whether a tiger is real or imaginary (hypotheticality); in making a financial investment, it is important whether a recession is anticipated in the near or distant future (temporal distance), here or somewhere else (spatial distance)" (Trope and Liberman 2010, p. 445).

11 Many thanks to an anonymous reviewer for pressing me on this.
} 
p. 8). In contrast, EP would argue that there need not be any 'mental control' of our action, and that we do not need to invoke representations to explain behavior. Rather, we are simply invited by the environment to carry out particular actions.

The current proposal makes use of AIT to empirically validate and substantiate the intuition that agents have a sense of what they are doing, which serves as a starting point for making the analogy with the sense of what is afforded. As such, it does not rely upon the AIT framework as a whole, but only upon certain aspects of it. ${ }^{12}$

Specifically, my proposal makes use of (1) the terminology of low- and high-level identities, and relies on (2) the idea that agents identify their actions (and affordances).

The first aspect that my account borrows from AIT seems quite unproblematic from an ecological perspective: if one assigns a particular affordance a low- or highlevel identity from the third-person perspective, one does not necessarily thereby incur any metaphysical commitments. Moreover, in much existing research on affordances it is commonplace to see them described as 'relevant' or 'meaningful'. Although these terms are then used interchangeably, the goal of this paper is to move beyond this state of affairs by further determining how, precisely, an object or its affordance matters to the agent. The terminology of low- and high-level identities allows for this differentiation by indicating the structural relations between actions (e.g. Goldman 1970; MacIntyre 1984).

The second aspect of AIT which I make use of in my account perhaps raises a more pressing issue, with regards to its ecological credentials. The skeptic might say that when an agent 'identifies' an action identity (or the identity of a possibility for action) the agent engages in an act of reflection. That is, acts of identification would presuppose some form of 'mental control' on perception and action. This would indeed be at odds with EP.

Crucially however, in this proposal, when I say that an agent identifies an affordance, this should not be understood as a conscious or reflective act of considering various possible identities and selecting one. Rather, saying that someone has identified an affordance is a description, from a third-person perspective, of what the agent has done. From a first-person perspective, the agent does not first decide on an identity before engaging with the act. Instead an identification should be seen as resulting from a variety of factors. For instance, whether an empty soda can on the ground is experienced as affording 'picking up' depends on the agents bodily configuration, her skills, and social conventions (cf. Withagen et al. 2012). But, and this has been the focus of the present paper, it can also depend on the agents' diachronic concerns. Who the agent is, broadly construed, what she cares about, how she sees herself, who she has been, who she would like to become-all of those factors may affect how she experiences a particular object. So, much like a person in a wheelchair need not first decide that a staircase is not relevant for her to be experienced as irrelevant, an agent experiences what an object affords unreflectively, as the result of who she is (broadly construed). Similarly, when a life-long vegetarian perceives a steak on the barbecue she requires no conscious or explicit reflection on her values in order to ensure that she does not identify the steak's affordance as 'affording eating' (Dings 2020b). Rather,

\footnotetext{
12 This is important because, given the quotes by Vallacher and Wegner, it is likely that AIT and EP are incompatible in some respects.
} 
possibilities for action are enacted, and the rich phenomenology of meaningfulness stems from the holistic complexity of the personal characteristics (cf. Dings 2018).

In addition to identities being enacted there is a pivotal role for context in driving our identifications (as Vallacher and Wegner 1987, p. 6 also acknowledge). That is, contextual cues serve as an important guide in our identifications. This also indicates the interrelation between 'a sense of what one is doing' and 'a sense of what is afforded': in one and the same context, you are performing an action and whilst doing so becoming invited to another (cf. Van Dijk and Rietveld (2018) on how affordances are 'nested'). For instance, if the sense of what I am doing entails 'contributing to society by picking up trash' (as opposed to simply picking up trash) then the sense of what is afforded might also differ: other objects that are relevant to 'contributing to society' but not to trash-picking, such as an elderly person having difficulty crossing the street, could become salient and inviting. In contrast, if you have a different set of diachronic concerns (e.g. you are a passionate collector of soda cans) then an empty can on the street might be experienced as 'expanding your collection', and given that context, the elderly person might be experienced differently as well.

In sum, although future research should further investigate possible the promises and pitfalls in integrating AIT and EP, the current proposal only relies on those components of AIT that are compatible with EP's central tenets.

\section{Meaningful affordances: implications for authentic and autonomous agency}

In this section we apply the developed proposal to the context of authenticity and autonomy. Let me therefore summarize where we are currently at. We started with the accusation that affordances were 'not meaningful' in the sense that they could not accommodate the diversity in how things 'matter' to an individual. This would be problematic for their application to debates on e.g. autonomous and authentic agency, where the meaningfulness of experience is pivotal. I continued to offer an analysis of affordance-experience that emphasizes the particularly human components of agency (e.g. diachronicity and self-interpretation) and that draws on existing research (e.g. AIT), to show that people have a sense of what they are doing whilst acting, and analogously, a sense of what is afforded. This leads to the following claim: meaningful affordances are those instances where a possibility for action is identified at a relatively high level, which means that the affordance is experienced in light of the agent's diachronic and interconnected concerns.

Regarding debates on authenticity and autonomy, we are now in a position to elucidate the role of meaningful affordances for those debates. I will first make a more theoretical point on why meaningful affordances play an important role in understanding authenticity and autonomy, and then turn to some recent accounts and see how this proposal benefits those. 


\subsection{A relational approach to 'what moves us'}

Many discussions on authenticity and autonomy revolve around what is sometimes called the locus of control, which may be experienced as internal or external. This feature of our agency pertains to the experience that an action flows 'from you'; that you are 'in charge' or the source of where an action originates from (regardless of whether you were actually the source of that action; one can experience an internal locus of control without being in control). Although it goes beyond the scope of the present paper to provide a full overview of research on this issue, consider that it is something that is acknowledged across a range of fields. In philosophy, this view was championed by Harry Frankfurt who talks about the moving principle of an action, which can be internal or external (Frankfurt 1988). According to Frankfurt, what moves us can be experienced as something internal or external. When someone pushes me, or when I have a spasm, I feel as if I am moved by an external source. In contrast, when I wholeheartedly perform a certain action, this moving principle is experienced as purely internal. Likewise, in the phenomenology of agency, it is argued that you sometimes experience yourself as the source of an action, when the act is "immanently generated" (cf. Horgan et al. 2003). And we find similar views in psychology. The highly influential self-determination theory (Ryan and Deci 2017) assumes that people can be intrinsically motivated, where the locus of control lies within the individual, or extrinsically motivated, where the locus of control lies outside of the individual. Furthermore, AIT adopts a similarly dichotomous view where you are moved either by your own doing or because of the situation (i.e. personal vs. situational causation, cf. Vallacher and Wegner 1989, p. 10).

I do not have space here to do justice to the complexities and peculiarities of these theoretical positions. What is relevant for present purposes are two points. First, that these theories adopt (often implicitly) a more or less Cartesian framework where an action is seen as either originating from within or from outside. Second, that these and other theories assume that only actions that originate from within are relevant for autonomy and authenticity. That is, only the 'internal moving principles' or 'intrinsic motivations' or 'internal loci of control' are deemed relevant for authenticity and autonomy. That is, one is only truly self-determining or self-governing when a moving principle is internal, and we experience a moving principle as internal when an action follows from my reflective deliberations.

However, the current proposal suggests that the Cartesian picture that these theories (implicitly) adopt is flawed (cf. Weichold 2018). Specifically, speaking in terms of internality-externality, of actions originating either from within or from outside, is flawed. On the current proposal, there may be 'moving principles' that technically lie outside of the agent but which are nevertheless experienced, when acted upon, as having an internal locus of control. That is, when I am solicited by a meaningful affordance (i.e. a possibility for action that is in line with my diachronic concerns), then this 'external' attractor may still give rise to an autonomous or authentic agential self-experience.

As such, the proposed re-conceptualization of affordances offers a non-Cartesian conceptual underpinning for recent research on relational views on authenticity, where 
it is the 'fit' or 'match' between the agent and its environment that leads to an internal locus of control.

To illustrate, consider various studies in psychology on what is called 'state' authenticity. This research is concerned with elucidating when people 'feel like themselves', i.e. feel authentic. A series of recent studies has shown that people feel like themselves when there is precisely a 'fit' with their environment (Lenton et al. 2013; Schmader and Sedikides 2018). Moreover, the current proposal offers a supplement to writings from a more philosophical perspective that similarly highlight relationality (see e.g. Mackenzie and Stoljar 2000). Most of these focus exclusively on social relations, but other accounts are relational in a broader sense and also incorporate the materiality of our environment. In doing so, they explicitly make use of the affordance-concept. Let me now turn to those accounts and see how the current proposal supplements those.

\subsection{Authenticity, autonomy and affordances}

De Haan et al. (2013) try to make sense of the treatment effect of deep brain stimulation (DBS) for psychiatric patients (specifically patients suffering from obsessive-compulsive disorder). Adopting an enactive-affordance based framework, they investigate the alterations in patients' fields of affordance as they undergo the DBS treatment. They summarize their conclusion by saying that "[the patients'] field of affordances now [i.e. following the DBS treatment] reflects their concerns beyond the mere urge to reduce the strong tension and anxiety. That is, their field of affordances now reflect what really matters to them once the distortion of anxiety is lifted" (De Haan et al. 2013 , p. 8, italics added). Thus, De Haan et al. try to construe authenticity in terms of an alteration in the individual's field of affordances.

Shaun Gallagher adopts a similar strategy with regard to autonomy. In a recent series of papers (Gallagher 2018a, b; Gallagher and Janz 2018) he suggests that

we can think of autonomy in terms of the affordances available to a particular situated agent, where that situation is both physical and social. A higher number of affordances (i.e., range and temporal proximity), together with a better quality of affordances (i.e., salience and affective allure), roughly correlates with greater autonomy and directly relates to one's sense of agency.

What is particularly relevant for present purposes are the two dimensions of the field of affordances that Gallagher calls their 'quality' — what De Haan et al. (2013) called their salience and affective allure. In a nutshell, it remains unclear what this quality consists of. Indeed it seems to be precisely this lack of clarity that enables the skepticism by Ratcliffe and Broome (in press) regarding the usefulness of affordances. Merely acknowledging that affordances can have a particular salience or affective allure is not sufficient for making affordances useful for autonomy and authenticity. What is needed, as Ratcliffe and Broome indicated, are more nuanced distinctions regarding the diversity in how an affordance can be salient, soliciting, relevant or affectively alluring.

The current proposal sheds light on this issue. I want to argue that the dimension of low- and high-level identification of an affordance, i.e. its meaningfulness or 
embeddedness in diachronic concerns, is what contributes to its quality (specifically its affective allure). So what really matters to the patient in De Haan et al.'s quote are those affordances that I have described as meaningful. ${ }^{13}$ It are these affordances that need to be taken into account when investigating an agents' authenticity or autonomy, as it is not any possibility for action that affects our autonomous or authentic agency, but particularly those that are connected to our diachronic concerns. ${ }^{14}$

To put both problem and solution a bit differently: A field of affordances by definition reflects what matters to the agent (Rietveld et al. 2018). But as we've seen in the beginning of this paper, 'what matters' is a diverse set of experiences. So we need to differentiate. What I am arguing here is that some affordances matter in the sense of being 'merely relevant' (i.e. identified at a low-level) whereas other affordances matter in the sense of being 'meaningful' (i.e. identified at a higher-level). So a field of affordances that reflects autonomy and authenticity has a particular 'level of personal agency', in Vallacher and Wegner terms, i.e. "the degree to which an individual has organized her actions into abstract meaningful categories that can channel behavior into dispositional tendencies" (Vallacher and Wegner 2011, p. 338). See also Vallacher and Wegner (1989).

To illustrate my point using a non-hypothetical example, consider the following case provided by a study on affective experience by De Leersnyder et al. (2018). The example involves two individuals (Jasmin and Peter) who received their driver's license. Receiving their driver's license is experienced differently by both individuals:

Both Peter and Jasmine considered the situation of getting a driver's license 'emotional' and 'positive' because it was both relevant and conducive to a goal they had set for themselves. Yet, the situation was relevant to Peter because he had accomplished a personal goal, whereas it was relevant to Jasmine because it enabled her to help her family. Peter and Jasmine thus differed in the concerns they considered to be at stake in getting a driver's license (ambition and success vs. loyalty and helping others) - a difference we hypothesize to be linked to the difference in the emotions they experienced (pride for Peter, but pride, closeness and respect for Jasmine). (De Leersnyder et al. 2018, p. 598).

What I argued for in Dings (2020a) is that we can extend these findings to how agents might experience affordances (something that De Leersnyder et al. seem to allow for). The original study indicates that Peter and Jasmin's diachronic concerns affect how they experience the license. Analogously, I want to argue that how they experience what the license affords depends on who they are (broadly construed). This means that Jasmin experiences the license as a more meaningful affordance than Peter, precisely because getting the license is inextricable from, and has repercussions for, various other concerns of Jasmin. In fact, the study reports Jasmin saying that receiving the license "means I can final bring my children to a mall or to the McDonald's every

\footnotetext{
13 It is interesting to note that in the debate on DBS-induced changes, some have argued that it is in fact narrativity that best captures "what matters" to the patient (cf. Goddard 2017). The current proposal offers a way of bridging De Haan et al.'s (2013) affordance-based account with Goddard's (2017) narrative account, by indicating how narrative meaning can be experienced in terms of relevant affordances.

14 In Dings (2018, 2019) I described the agential phenomenology of meaningfulness in terms of 'mineness', a term which similarly highlights the embeddedness of an experience in the agent's diachronic concerns.
} 
now and then. I can also take the car shopping, so that my family doesn't have to carry heavy groceries anymore" (ibid., p. 597). Now the point is that although Jasmin and Peter's field of affordances have both increased in quantity, only Jasmin's field of affordances has undergone a qualitative change, such that receiving the license increases her authentic and autonomous agency (we do not have sufficient information about Peter's background to fully determine any qualitative changes in his field of affordances).

\section{Conclusion and questions for future research}

In this paper I offered a reconceptualization of affordances that allows us to make sense of meaningful experience. This reconceptualization rebuts recent criticisms of the affordance-concept (of e.g. Ratcliffe and Broome in press) and makes it more suitable to be applied in research domains where the agential phenomenology plays an important role. Regarding such domains, this paper has specifically investigated the importance of meaningful affordances for understanding authentic and autonomous agency.

Clearly, the proposal outlined in this paper is but a starting point for further discussion and research. There are many issues that require a more thorough investigation. These pertain to the proposal itself (its assumptions, arguments and validation) as well as to the research domains that this proposal has tried to place within the reach of affordance researchers (e.g. psychiatric contexts and the domains of autonomy and authenticity). Moreover, the issues that remain to be addressed include conceptual as well as empirical matters.

The conceptual matters primarily emerge as a result of this proposal's attempt to incorporate various research paradigms. For instance, to what extent can frameworks such as Action Identification Theory and Construal Level Theory be further integrated with (Gibsonian) ecological psychology? Although the current proposal is not strictly committed to any of those paradigms, I have hinted at such an integration and argued that it is worth exploring (see also Gallagher 2020). Yet a more thorough investigation is required to see to what extent these paradigms are commensurable. Such an investigation might start by looking into the compatibility of the current proposal with some recent affordance research that shares the aim of attempting to make the affordance-concept more applicable to domains outside of traditional ecological psychology (such as the already mentioned 'Skilled Intentionality Framework', cf. Rietveld and Kiverstein 2014; Bruineberg and Rietveld 2014; Rietveld et al. 2018).

As for empirical matters, the current proposal needs to be empirically validated. The claim that we experience affordances as meaningful and that this experience modulates our agency can, and should, be tested. Importantly, the proposal as it is outlined clearly allows for such testing. To illustrate, consider first that is shown that increasing mortality salience makes people adopt more high-level identities in their everyday actions (cf. Landau et al. 2011). That is, making agents aware of their mortality changes their sense of what they are doing such that actions that were previously trivial may now become connected to the agent's diachronic concerns. Taking into account the current proposal, an empirical investigation might target how agents experience and 
interact with affordances prior to and following an increase in mortality salience, to see whether and how meaningful experience modulates their agency. Another research domain where this could be put to the test involves studies on 'state authenticity' (Schmader and Sedikides 2018). Those studies show that people feel authentic when they are experiencing their environment in the 'right' way-when they experience a 'fit' between themselves and the world around them. The current proposal suggests that affordance-researchers may contribute to these studies by offering a more fine-grained analysis of how agents interact with their environment.

Acknowledgements Many thanks to Sanneke de Haan, Jelle Bruineberg, Ludger van Dijk, Sabrina Coninx, Adrian Downey and two anonymous reviewers for helpful comments on the paper and discussions on this topic. Also thanks to audiences at Amsterdam and Bochum where earlier versions of this paper were presented.

Funding Open Access funding enabled and organized by Projekt DEAL. Gefördert durch die Deutsche Forschungsgemeinschaft (DFG)—419046236 (DFG Forschungsgruppe FOR2812 'Szenarien der Vergangenheit'); GRK-2185/1 (DFG-Graduiertenkolleg Situated Cognition). Funded by the Deutsche Forschungsgemeinschaft (DFG, German Research Foundation) - 419046236 (DFG Research Unit FOR2812 'Constructing scenario's of the past'); GRK-2185/1 (DFG Research Training Group Situated Cognition)

Availability of data and materials Not applicable.

Coda availability Not applicable.

\section{Compliance with ethical standards}

\section{Conflict of interest None.}

Open Access This article is licensed under a Creative Commons Attribution 4.0 International License, which permits use, sharing, adaptation, distribution and reproduction in any medium or format, as long as you give appropriate credit to the original author(s) and the source, provide a link to the Creative Commons licence, and indicate if changes were made. The images or other third party material in this article are included in the article's Creative Commons licence, unless indicated otherwise in a credit line to the material. If material is not included in the article's Creative Commons licence and your intended use is not permitted by statutory regulation or exceeds the permitted use, you will need to obtain permission directly from the copyright holder. To view a copy of this licence, visit http://creativecommons.org/licenses/by/4.0/.

\section{References}

Arndt, J., Landau, M. J., Vail, K. E., III, \& Vess, M. (2013). An edifice for enduring personal value: A terror management perspective on the human quest for multilevel meaning. Markman, Proulx \& Lindberg, 2013, 49-69.

Baggs, E., \& Chemero, A. (2019). The third sense of environment. In J. B. Wagman \& J. J. Blau (Eds.), Perception as information detection: Reflections on Gibson's ecological approach to visual perception (pp. 5-20). New York: Routledge.

Brancazio, N., \& Segundo-Ortin, M. (2020). Distal engagement: Intentions in perception. Consciousness and Cognition, 79, 102897.

Brandon, P. (2016). Body and self: An entangled narrative. Phenomenology and the Cognitive Sciences, 15(1), 67-83.

Bruineberg, J., \& Rietveld, E. (2014). Self-organization, free energy minimization, and optimal grip on a field of affordances. Frontiers in Human Neuroscience, 8, 599. 
Chemero, A. (2003). An outline of a theory of affordances. Ecological Psychology, 15(2), 181-195.

Colombetti, G. (2014). The feeling body. Affective science meets the enactive mind. Cambridge: MIT Press.

Costall, A. (1995). Socializing affordances. Theory \& Psychology, 5(4), 467-481.

Costall, A. (2015). Canonical affordances and creative agency. In: Glăveanu, V. P., Gillespie, A., \& Valsiner, J. (Eds.), Rethinking creativity: Contributions from social and cultural psychology, 45-57.

De Haan, S. (2020). Enactive psychiatry. Cambridge: Cambridge University Press.

De Haan, S., Rietveld, E., Stokhof, M., \& Denys, D. (2013). The phenomenology of deep brain stimulationinduced changes in OCD: An enactive affordance-based model. Frontiers in Human Neuroscience, 7 , 653.

De Leersnyder, J., Koval, P., Kuppens, P., \& Mesquita, B. (2018). Emotions and concerns: Situational evidence for their systematic co-occurrence. Emotion, $18(4), 597$.

Dings, R. (2018). Understanding phenomenological differences in how affordances solicit action. An exploration. Phenomenology and the Cognitive Sciences, 17(4), 681-699.

Dings, R. (2019). The dynamic and recursive interplay of embodiment and narrative identity. Philosophical Psychology, 32(2), 186-210.

Dings, R. (2020a). Psychopathology, phenomenology and affordances. Phenomenology \& Mind, 18, 56-66.

Dings, R. (2020b). Can ecological psychology account for human agency and meaningful experience? Constructivist Foundations, 15(3), 220-222.

Frankfurt, H. G. (1988). The importance of what we care about: Philosophical essays. Cambridge: Cambridge University Press.

Gallagher, S. (2012). Multiple aspects in the sense of agency. New Ideas in Psychology, 30(1), 15-31.

Gallagher, S. (2017). Enactivist Interventions: Rethinking the Mind. Oxford: University Press.

Gallagher, S. (2018a). Deep brain stimulation, self and relational autonomy. Neuroethics. https://doi.org/1 $0.1007 / \mathrm{s} 12152-018-9355-\mathrm{x}$.

Gallagher, S. (2018b). The therapeutic reconstruction of affordances. Res Philosophica, 95(4), 719-736.

Gallagher, S. (2020). Action and interaction. Oxford: Oxford University Press.

Gallagher, S., \& Janz, B. (2018). Solitude, self and autonomy. Discipline filosofiche, 28(2), 159-175.

Gallagher, S., \& Marcel, A. J. (1999). The self in contextualized action. Journal of Consciousness Studies, 6(4), 4-30.

Gibson, J. J. (1966). The senses considered as perceptual systems. Boston: Houghton Mifflin.

Gibson, J. J. (1979). The ecological approach to visual perception. New York, NY: Taylor \& Francis.

Glenberg, A. M. (1997). What memory is for. Behavioral and Brain Sciences, 20(1), 1-19.

Goddard, E. (2017). Deep brain stimulation through the "lens of agency": Clarifying threats to personal identity from neurological intervention. Neuroethics, 10(3), 325-335.

Goldman, A. I. (1970). Theory of human action. Princeton: Princeton University Press.

Heft, H. (1989). Affordances and the body: An intentional analysis of Gibson's ecological approach to visual perception. Journal for the Theory of Social Behaviour, 19(1), 1-30.

Heft, H. (2001). Ecological psychology in context: James Gibson, Roger Barker, and the legacy of William James's radical empiricism. Hillsdale: Lawrence Erlbaum Assoc Incorporated.

Heras-Escribano, M. (2020). Précis of The philosophy of affordances. Constructivist foundations, 15(3), 199-213.

Horgan, T. E., Tienson, J. L., \& Graham, G. (2003). The phenomenology of first-person agency. In S. Walter \& H.-D. Heckmann (Eds.), Physicalism and mental causation (pp. 323-341). Exeter: Imprint Academic.

Jeuk, A. A. (2019). Concern and the structure of action. HUMANA. MENTE Journal of Philosophical Studies, 12(35), 249-270.

Landau, M. J., Kosloff, S., \& Schmeichel, B. J. (2011). Imbuing everyday actions with meaning in response to existential threat. Self and Identity, 10(1), 64-76.

Lenton, A. P., Bruder, M., Slabu, L., \& Sedikides, C. (2013). How does "being real" feel? The experience of state authenticity. Journal of Personality, 81(3), 276-289.

MacIntyre, A. (1984). After virtue. Notre Dame, IN: University of Notre Dame Press.

Mackenzie, C., \& Stoljar, N. (Eds.). (2000). Relational autonomy: Feminist perspectives on autonomy, agency, and the social self. Oxford: Oxford University Press.

Markman, K. D., Proulx, T. E., \& Lindberg, M. J. (2013). The psychology of meaning. Washington: American Psychological Association.

McGann, M. (2007). Enactive theorists do it on purpose: Toward an enactive account of goals and goaldirectedness. Phenomenology and the Cognitive Sciences, 6(4), 463-483. 
Michaels, C. F. (2003). Affordances: Four points of debate. Ecological Psychology, 15(2), 135-148.

Michaels, C. F., \& Carello, C. (1981). Direct perception. Englewood Cliffs, NJ: Prentice-Hall.

Mojica, L. (2020). Reclaiming meaning, reclaiming normativity. Constructivist foundations, 15(3), 216-218.

Ramstead, M. J., Veissière, S. P., \& Kirmayer, L. J. (2016). Cultural affordances: Scaffolding local worlds through shared intentionality and regimes of attention. Frontiers in Psychology, 7, 1090.

Ratcliffe, M. (2015). Experiences of depression. A study in phenomenology. Oxford: Oxford University Press.

Ratcliffe, M. (2017). Selfhood, schizophrenia, and the interpersonal regulation of experience. In C. Durt, T. Fuchs, \& C. Tewes (Eds.), Embodiment, enaction, and culture: Investigating the constitution of the shared world (pp. 149-171). Cambridge, MA: MIT Press.

Ratcliffe, M., \& Broome, M. (in press). Beyond "salience" and "affordance": Understanding anomalous experiences of significant possibilities. In S. Archer (Ed.), Salience. London: Routledge.

Rietveld, E. (2008). Situated normativity: The normative aspect of embodied cognition in unreflective action. Mind, 117(468), 973-1001.

Rietveld, E. (2012). Context-switching and responsiveness to real relevance. In M. Wheeler \& J. Kiverstein (Eds.), Heidegger and cognitive science (pp. 105-135). London: Palgrave Macmillan.

Rietveld, E., Denys, D., \& Van Westen, M. (2018). Ecological-enactive cognition as engaging with a field of relevant affordances. In A. Newen, L. C. De Bruin, \& S. Gallagher (Eds.), The Oxford handbook of $4 E$ cognition (p. 41). Oxford: Oxford University Press.

Rietveld, E., \& Kiverstein, J. (2014). A rich landscape of affordances. Ecological Psychology, 26(4), $325-352$.

Ryan, R. M., \& Deci, E. L. (2017). Self-determination theory: Basic psychological needs in motivation, development, and wellness. New York: Guilford Publications.

Schmader, T., \& Sedikides, C. (2018). State authenticity as fit to environment: The implications of social identity for fit, authenticity, and self-segregation. Personality and Social Psychology Review, 22(3), 228-259.

Taylor, C. (1985). Philosophical papers: Human agency and language (Vol. 1). Cambridge: Cambridge University Press.

Trope, Y., \& Liberman, N. (2010). Construal-level theory of psychological distance. Psychological Review, $117(2), 440$.

Vallacher, R. R., \& Wegner, D. M. (1987). What do people think they're doing? Action identification and human behavior. Psychological Review, 94(1), 3.

Vallacher, R. R., \& Wegner, D. M. (1989). Levels of personal agency: Individual variation in action identification. Journal of Personality and Social Psychology, 57(4), 660.

Vallacher, R. R., \& Wegner, D. M. (2011). Action identification theory. In P. Van Lange, A. W. Kruglanski, \& E. Tory Higgins (Eds.), Handbook of theories of social psychology (Vol. 1, pp. 327-349). Thousand Oaks, CA: SAGE.

Van Dijk, L., \& Rietveld, E. (2018). Situated anticipation. Synthese. https://doi.org/10.1007/s11229-018-0 2013-8.

Weichold, M. (2018). Situated agency: Towards an affordance-based, sensorimotor theory of action. Phenomenology and the Cognitive Sciences, 17(4), 761-785.

Withagen, R. (2018). Towards an ecological approach to emotions and the individual differences therein. New Ideas in Psychology, 51, 21-26.

Withagen, R., De Poel, H. J., Araújo, D., \& Pepping, G. J. (2012). Affordances can invite behavior: Reconsidering the relationship between affordances and agency. New Ideas in Psychology, 30(2), 250-258.

Publisher's Note Springer Nature remains neutral with regard to jurisdictional claims in published maps and institutional affiliations. 